\title{
Relationship Between Intrapreneurship and Customer Driven Behaviors (Case of Sports Istanbul)
}

\author{
Haluk Saçaklı ${ }^{1}$, Aydın Pekel ${ }^{2}$, Abdurrahman Kepoğlu ${ }^{3}$ \\ ${ }^{1}$ School of Physical Education and Sports, Istanbul Gelisim University, Istanbul, Turkey \\ ${ }^{2}$ Health Sciences Institute Department of Physical Education and Sports, Muğla Sitkı Koçman University, Muğla, \\ Turkey \\ ${ }^{3}$ Faculty of Sport Sciences, Muğla Sitkı Koçman University, Muğla, Turkey \\ Correspondence: Haluk Saçakl1, Physical Education and Sports, Istanbul Gelisim University, Istanbul, Turkey.
}

Received: March 4, 2019

Accepted: March 21, 2019

Online Published: March 24, 2019

doi:10.11114/jets.v7i4.4115

URL: https://doi.org/10.11114/jets.v7i4.4115

\begin{abstract}
The aim of this study is to evaluate the relationship between the intrapreneurship and customer driven behaviors of the sports organization personnel. For this purpose, 1789 personnel working in Istanbul Sports Activities and Management Trade Incorporated Company, which serves within Istanbul Metropolitan Municipality have composed the population of the study and the sample is composed of 360 volunteer participants determined by simple random sampling method. The study was performed by scanning method (relational model) and the data was collected by survey method. The personal information form, the internal entrepreneurship scale, and the customer-oriented behavior scale were administered to the participants. The obtained data were analyzed using SPSS 24 software package program. Correlation and regression analysis were used as statistical methods. As a result, it is determined that there is a significant relationship between intrapreneurship and customer-driven behaviors and that intrapreneurship behavior has a decisive effect on the level of customer-driven behavior. Findings indicate that sub-dimensions of intrapreneurship have a certain degree of impact on the sub-dimensions of customer-driven behavior.
\end{abstract}

Keywords: sports organization, intrapreneurship, customer-driven behavior

\section{Introduction}

The delivery of sports products and services to consumers and the development of sports-specific marketing strategies have gained importance in recent years (Ekmekçi \& Ekmekçi, 2010). Sports services of which the importance increases on a daily basis for the development of the economy of the country (Uygun, Güner \& Mete, 2013). whether profit-oriented or non-profit-making, feel the pressure to find new and effective methods that will satisfy their consumers, and create value for market offerings that will reach their targeted consumers and reach their desired goal (Uygun, 2016). Why is this problem important?

Having the desired profits, management of processes which are effective in customer interactions and developing sports industry has become a more significant function for success. An effective management approach in sports services industry can be applied by providing opportunities to improve and develop the personnel with innovative and beneficial strategies. This shows the importance of intrapreneurship behavior practices in order to provide customer-driven behavior and customer satisfaction in sports service enterprises as in the service industry. There are various definitions of the concept of intrapreneurship. Mariano et al. (2014) explained intrapreneurship "as a concept used to explain entrepreneurial behaviors in the existing organization".

The consideration of the opinions and wishes of the service employees by the managers can be an important factor for the development of customer satisfaction, organizational commitment, and customer driven behaviors. (Narver \& Slater, 1990) state that "being customer driven means to understand the customer value chain that covers the existing and future changes". (Akın, 2017) describes being customer driven as the "Interactions by customers by using the concepts of marketing". It is seen that the development of intrapreneurship behaviors by service personnel is an important factor in terms of ensuring external customer satisfaction. For this reason, the problem statement of the study can be defined as examining the relationship between sports organization personnel and intrapreneurship and customer driven behaviors. 


\section{Materials and Methods}

The aim of this study is to evaluate the relationship between intrapreneurship and customer driven behavior of sports organization personnel. In this respect, the relational model of research that aims to determine the presence and/or degree of coexistence between two or more variables (Karasar, 2008), (Ekici \& Hevedanl1 2010). For this purpose, 1789 personnel working in Istanbul Sports Activities and Management Trade Incorporated Company, which serves within Istanbul Metropolitan Municipality have composed the population of the study and the sample is composed of 360 volunteer participants determined by simple random sampling method. After examining the answers of the participants to the scales, the missing and incorrect ones were not taken into consideration and the scales of 360 participants were used.

\subsection{Data Collection Tools}

Descriptive form created by the researcher consists of 6 questions on gender, marital status, education level, age, professional experience, and income level. In order to measure the level of intrapreneurship behavior of the participants, an intrapreneurship behavior scale developed by Uygun et al. (2013), Donovan et al. (2004) (Stewart, 2009) consisting of 22 items and 4 sub-dimensions for which validity and reliability analysis has been was done was administered to the sample population. Intrapreneurship behavior scale consists of four sub-dimensions namely innovation (6 items), risk-taking (6 items), taking initiative and prediction (6 items), general intrapreneurship tendency (4 items). The total of the 22 items representing intrapreneurship behavior accounted for $53.91 \%$ of the total variance. For the scale of intrapreneurship behavior, values of $90 \mathrm{KMO}$ and $\mathrm{p}=0,000<0,01$ indicate that the data are suitable for factor analysis. The scale has the measuring quality of Likert type equally spaced with (1) "I Strongly Disagree" to (5) "I Strongly Agree" (Uygun \& Akın 2017). Include in these subsections the information essential to comprehend and replicate the study. Insufficient detail leaves the reader with questions; too much detail burdens the reader with irrelevant information. Consider using appendices and/or a supplemental website for more detailed information.

\subsection{Participant (Subject) Characteristics and Sampling Procedures}

The aim of this study is to evaluate the relationship between intrapreneurship and customer driven behavior of sports organization personnel. In this respect, the relational model of research that aims to determine the presence and/or degree of coexistence between two or more variables (Karasar, 2008), (Ekici \& Hevedanl1 2010). For this purpose, 1789 personnel working in Istanbul Sports Activities and Management Trade Incorporated Company, which serves within Istanbul Metropolitan Municipality have composed the population of the study and the sample is composed of 360 volunteer participants determined by simple random sampling method. After examining the answers of the participants to the scales, the missing and incorrect ones were not taken into consideration and the scales of 360 participants were used.

Cronbach's Alpha values indicate that the scale and the sub-dimensions of the scale are relatively reliable. Customer Driven Scale explains $69.7 \%$ of the total variance. The scale has the measuring quality of Likert type equally spaced with (1) "I Strongly Disagree" to (5) "I Strongly Agree" (Uygun \& Akin 2017).

\section{Results}

\subsection{Statistical Analysis}

The data obtained from personal information form, intrapreneurship and customer driven scales were entered into SPSS 22.0 package program and were analyzed. Personal information, inventory averages, and factor scores were provided by determining the frequency (f) and percentage (\%) values of the participants. The parametric and non-parametric distribution of the data were analyzed by focusing on parametric and non-parametric distribution curves and skewness-kurtosis values. Data have parametric distribution. Pearson Correlation and Regression Analysis were used as the statistical process.

Table 1 inferred that $66.1 \%$ of the participants were male, $33.9 \%$ were female; $33.1 \%$ were single, $66.9 \%$ were married; $21.7 \%$ were high school graduates, $78.3 \%$ were university graduates; $18.6 \%$ were between $22-25$ years old, $16.7 \%$ were $26-29$ years, $30.3 \%$ were $30-35$ years old and $34.4 \%$ were 36 or older; $41.4 \%$ had work experience between $1-5$ years, $33.9 \%$ had work experience between 6-10 years, $14.4 \%$ had work experience between 11-15 years and $10.3 \%$ had work experience for 16 years and above; and 33.1\% had a level of income between 2500-3500 TRY, $41.1 \%$ had a level of income between 3501-4500 TRY and $25.8 \%$ had a level of income of 4501 TRY and above. 
Table 1. Socio-Demographical Characteristics of Participants

\begin{tabular}{llll}
\hline Variables & Sub-Variables & Frequency & Percentage \\
\hline \multirow{3}{*}{ Gender } & Male & 238 & 66.1 \\
& Female & 122 & 33.9 \\
Marital Status & Total & 360 & 100.0 \\
& Single & 119 & 33.1 \\
Education Level & Torried & 241 & 66.9 \\
& High School & 360 & 100.0 \\
& University & 78 & 21.7 \\
Tge & Total & 282 & 100.0 \\
& $22-25$ & 360 & 18.6 \\
& $26-29$ & 67 & 16.7 \\
& $30-35$ & 60 & 30.3 \\
Work Experience & 36 and above & 109 & 34.4 \\
& Total & 124 & 100.0 \\
& $1-5$ & 360 & 41.4 \\
Income Level & $6-10$ & 149 & 33.9 \\
& $11-15$ & 122 & 14.4 \\
& 16 years and above & 52 & 10.3 \\
& Total & 37 & 100.0 \\
& $2500-3500$ TRY & 360 & 33.1 \\
& $3501-4500$ TRY & 119 & 41.1 \\
& 4501 TRY and above & 148 & 25.8 \\
& Total & 93 & 100.0 \\
\hline
\end{tabular}

Table 2. Reliability Analysis Scores Related with Scales

\begin{tabular}{lllllll}
\hline & General & \multicolumn{6}{c}{ Cronbach's Alpha Factors, Sub Dimensions } \\
\hline & & $\mathbf{1}$ & $\mathbf{2}$ & $\mathbf{3}$ & $\mathbf{4}$ & $\mathbf{5}$ \\
Intrapreneurship & .789 & .714 & .730 & .824 & .860 & - \\
Customer Driven Behavior & .900 & .884 & .839 & .805 & .771 & .820 \\
\hline
\end{tabular}

Table 2 indicates that the Cronbach's Alfa values obtained for each scale have the results that scales and their sub-dimensions are reliable at an adequate level. The data provided by the participants on the relevant scales are consistent within themselves.

Table 3. Relationship Between Intrapreneurship and Customer Driven Behavior

\begin{tabular}{|c|c|c|c|c|c|c|c|}
\hline & & $\begin{array}{l}\text { Special } \\
\text { Attention to } \\
\text { Customer }\end{array}$ & $\begin{array}{l}\text { Understanding } \\
\text { the Needs of } \\
\text { Customers }\end{array}$ & $\begin{array}{l}\text { Providing } \\
\text { Required } \\
\text { Services }\end{array}$ & $\begin{array}{l}\text { Developing } \\
\text { Personal } \\
\text { Relations }\end{array}$ & $\begin{array}{l}\text { Service } \\
\text { Readiness }\end{array}$ & $\begin{array}{l}\text { Customer } \\
\text { Driven } \\
\text { Ability }\end{array}$ \\
\hline & $\mathrm{r}$ & $.469^{* *}$ & .119 & $.270^{* * *}$ & $.176^{* * *}$ & $.181^{* * *}$ & $.246^{* *}$ \\
\hline Innovativeness & $\mathrm{p}$ & .000 & .065 & .000 & .006 & .005 & .000 \\
\hline \multirow{2}{*}{ Risk Taking } & $\mathrm{r}$ & .213 & $.281^{* *}$ & $.176^{* * *}$ & $.263^{* *}$ & $.224^{* *}$ & $.274^{* *}$ \\
\hline & $\mathrm{p}$ & .021 & .000 & .006 & .000 & .000 & .000 \\
\hline \multirow{2}{*}{$\begin{array}{l}\text { Taking Initiative } \\
\text { and Prediction }\end{array}$} & $\mathrm{r}$ & $.314^{* * *}$ & $.315^{* *}$ & $.208^{* *}$ & .124 & $.232^{* *}$ & $.265^{* *}$ \\
\hline & $\mathrm{p}$ & .000 & .000 & .001 & .056 & .000 & .000 \\
\hline \multirow{2}{*}{$\begin{array}{l}\text { Intrapreneurship } \\
\text { Tendency }\end{array}$} & $\mathrm{r}$ & $.215^{* * *}$ & $.265^{* *}$ & $.187^{* *}$ & .081 & $.232^{* *}$ & $.205^{* *}$ \\
\hline & $\mathrm{p}$ & .001 & .000 & .004 & .214 & .000 & .001 \\
\hline \multirow{2}{*}{ Intrapreneurship } & $\mathrm{r}$ & $.315^{* *}$ & $.322^{* * *}$ & $.304^{* * *}$ & $.313^{* * *}$ & $.357^{* *}$ & $.455^{* *}$ \\
\hline & $\mathrm{p}$ & .000 & .000 & .000 & .001 & .000 & .000 \\
\hline
\end{tabular}

Table 3 shows that the direction and level of the relationship between intrapreneurship and customer driven characteristics. We can infer that a medium level and positive directed relation between the innovativeness and special attention to customer as sub-dimensions of intrapreneurship and customer driven behavior; a weak level and positive directed relation between understanding the needs of customers, providing the necessary services, developing personal relations and service readiness and total score of customer driven behavior; weak level and positive directed relation between the sub dimension of intrapreneurship named risk taking and between understanding the needs of customers, providing the necessary services, developing personal relations and service readiness and total score of customer driven behavior; medium level and positive directed relation between the sub dimension of intrapreneurship named initiative 
taking and prediction and between special attention to customers and understanding the needs of customers, and a weak level and positive directed relation providing the necessary services, developing personal relations and service readiness and total score of customer driven behavior; medium level and positive directed relation between the total score of intrapreneurship named risk taking and between understanding the needs of customers, providing the necessary services, developing personal relations and service readiness and total score of customer driven behavior.

Table 4. Regression Analysis Related with Customer Driven Behavior

\begin{tabular}{llll}
\hline & $\beta$ & $\mathrm{t}$ & $p$ \\
\hline Innovativeness & .397 & 5.567 & .000 \\
Risk Taking & .604 & 5.998 & .000 \\
Taking Initiative and Prediction & .402 & 4.097 & .000 \\
Intrapreneurship Tendency & .246 & 3.246 & .001 \\
& $\mathrm{R}=.455$ & $\mathrm{~F}(5.354)=18.480$ & \\
\hline
\end{tabular}

Table 4 inferred that there is a significant relationship between intrapreneurship tendency and customer driven behavior. $(\mathrm{R}=.455, \mathrm{R} 2=.207 ; \mathrm{p}<.050)$. It is seen that the variable of innovativeness with the Regression factor=.397, $\mathrm{t}=.5 .567$, $\mathrm{p}=.000$ values, risk-taking variable with the Standardized Regression factor $=.604, \mathrm{t}=.5 .998, \mathrm{p}=.000$ values, initiative taking and prediction variable with Standardized Regression factor $=.402, \mathrm{t}=4.09, \mathrm{p}=.000$ values and intrapreneurship tendency with Standardized Regression factor $=.246, \mathrm{t}=3.246, \mathrm{p}=.000$ values contribute to develop customer-driven behaviors. In other words, the most important or priority variables that determine the level of customer-driven behavior tendency of the participants are determined as risk-taking, taking initiative and prediction, innovation and intrapreneurship tendency. .207 R Square value which is obtained as a result of statistical analysis reveals that intrapreneurship behavior is the precursor of the level of customer-driven behavior and it is approximately $20.7 \%$ of the total variance.

\section{Discussion}

When the direction and level of the relationship between intrapreneurship and customer driven characteristics are examined; we see a medium level and positive directed relation between the innovativeness and special attention to customer as sub-dimensions of intrapreneurship and customer driven behavior; a weak level and positive directed relation between understanding the needs of customers, providing the necessary services, developing personal relations and service readiness and total score of customer driven behavior; weak level and positive directed relation between the sub dimension of intrapreneurship named risk taking and between understanding the needs of customers, providing the necessary services, developing personal relations and service readiness and total score of customer driven behavior; medium level and positive directed relation between the sub dimension of intrapreneurship named initiative taking and prediction and between special attention to customers and understanding the needs of customers, and a weak level and positive directed relation providing the necessary services, developing personal relations and service readiness and total score of customer driven behavior; medium level and positive directed relation between the total score of intrapreneurship named risk taking and between understanding the needs of customers, providing the necessary services, developing personal relations and service readiness and total score of customer driven behavior.Open the Discussion section with a clear statement of the support or nonsupport for your original hypotheses, distinguished by primary and secondary hypotheses. If hypotheses were not supported, offer post hoc explanations. Similarities and differences between your results and the work of others should be used to contextualize, confirm, and clarify your conclusions. Do not simply reformulate and repeat points already made; each new statement should contribute to your interpretation and to the reader's understanding of the problem.

The perceived level of increase in each sub-dimension of intrapreneurship will lead to a positive linear increase in the sub-dimensions of customer-driven characteristics and in the total score of customer-driven behavior. In this context, it can be said that the positive development of each sub-dimension of intrapreneurship behavior will contribute to a medium or weak level on customer-driven behavior of employees. We do not see any study examining the relationship between intrapreneurship and customer have driven behavior in the literature. However, there are some studies examining the relationship between intrapreneurship and customer driven behavior and different variables in their study, (Uygun \& Akın 2017) have focused on service business employees and have stated that there is a linear relationship between internal marketing perception and customer driven behavior, internal marketing perception and intrapreneurship behavior mostly as medium-sized positive ones. (Atar, 2015), it was stated that the improvements made for the personnel in the business contributed positively to the internal entrepreneurial and innovative identity of the personnel. Uygun et al. (2009) have stated in their study that depending on the level of the internal marketing application, the customer-driven characteristics of the employees could be differentiated. (Cingöz, 2011) concluded that "the realization of the advantages expected from intrapreneurship is through human resources practices, which should lead to the benefit of the employees". 


\section{Conclusions}

There is a significant relationship between intrapreneurship and customer-driven behavior. It is seen that the variables of intrapreneurship such as taking risks, taking initiative and prediction, innovation and intrapreneurship tendencies contribute to the development of customer-driven behaviors. In other words, the most important or priority variables that determine the level of customer-driven behavior tendency of the participants are determined as risk-taking, taking initiative and prediction, innovation and intrapreneurship tendency.

Findings indicate that sub-dimensions of intrapreneurship have a certain degree of impact on the sub-dimensions of customer-driven behavior. No studies have been found that examine the relationship between intrapreneurship and customer-driven behavior in the literature.

As a result, it is determined that there is a significant relationship between intrapreneurship and customer-driven behaviors and that intrapreneurship behavior has a decisive effect on the level of customer-driven behavior.

Giving priority to the development of intrapreneurship behavior in terms of customer driver characteristics provides important clues to ensure customer satisfaction in sports services. In order to encourage customer-driven behavior and to ensure customer expectation and satisfaction, it can be said conducting special applications where the sports organization staff will provide an independent opinion and supporting this personnel with positive feedback from managers will have a special impact.

\section{References}

Akın, P. D. (2017). The Role of Internal Marketing Practices in Customer and Intrapreneurship-Oriented Behaviors Development of Service Employees. Master Thesis. Aksaray University, Social Sciences Institute, Aksaray.

Atar, A. (2015). A study on the effects of strategic human resource management on organizational innovation and intrapreneurship: Research in the hotel industry. Master Thesis, Gazi University, Social Sciences Institute, Ankara.

Cingöz, A. (2011). Strategic human resource management and the effects of strategic human resource management on organizational performance and intrapreneurship: A survey of the manufacturing industry in Kayseri. Ph.D. Thesis, Erciyes University, Social Sciences Institute, Kayseri.

Donavan, D. T., Brown, T. J., \& Mowen, J. C. (2004). Internal Benefits of Service Worker Customer Orientation: Job Satisfaction, Commitment, and Organizational Citizenship Behaviors. Journal of Marketing, 68(January), 128-146. https://doi.org/10.1509/jmkg.68.1.128.24034

Ekici, G., \& Hevedanl1, M. (2010). Examining the attitudes of high school students towards biology in terms of different variables. Journal of Turkish Science Education, 7(4), 97-109.

Ekmekçi, R., \& Ekmekçi, Y. A. (2010). Sports Marketing. Pamukkale Journal of Sports Sciences, 1(1), 23-29.

Karasar, N. (2008). Scientific Research Methods. Nobel Publishing, Ankara.

Liao, J. F. (2009). The Effects of Internal Marketing on Customer Orientation in the Banking Industry. Ph.D. Thesis, Golden Gate University, San Fransisco.

Moriano, J. A., Molero, F., Topa, G., \& Mangin, J. P. L. (2014). The influence of transformational leadership and organizational identification on intrapreneurship. International Entrepreneurship and Management Journal, 10, 103-119. https://doi.org/10.1007/s11365-011-0196-x

Narver, J. C., \& Slater, S. F. (1990). The effect of a market orientation on business profitability. Journal of Marketing, 54, 20-35. https://doi.org/10.1177/002224299005400403

Stewart, J. K. (2009). An Investigation of an Entrepreneurial Orientation among Employees in Service Organization. $\mathrm{Ph} . \mathrm{D}$. Thesis, Ohio State University, Ohio.

Uygun, M. (2016). Space creation and consumer experience management of shopping centers as an experience venue: Gece Kitaplı̆̆ı Publishing: Ankara, Turkey, 2016

Uygun, M., \& Akın, P. D. (2017). The Role of Internal Marketing Practices in Customer and Intrapreneurship-Oriented Behaviors Development of Service Employees. Int. Journal of Management Economics and Business, ICMEB17 Special Issue, 836-853.

Uygun, M., Güner, E., \& Mete, S. (2013). The Role of Internal Customer Approach on Customer Orientation Behaviour of Employees in Service Businesses. Journal of Organizasyon ve Yönetim Bilimleri, 5(1), 129-149.

\section{Copyrights}

Copyright for this article is retained by the author(s), with first publication rights granted to the journal.

This is an open-access article distributed under the terms and conditions of the Creative Commons Attribution license which permits unrestricted use, distribution, and reproduction in any medium, provided the original work is properly cited. 